\title{
Urine IL-8 is the Predictive Biomarker of Steroid Sensitivity in Patients with Idiopathic Nephrotic Syndrome \\ $\mathrm{H} \mathrm{Xie}{ }^{1,2}, \mathrm{M} \mathrm{Fang}{ }^{2}, \mathrm{H} \mathrm{Lin}^{2}, \mathrm{P} \mathrm{Li}^{2}, \mathrm{~N} \mathrm{Sun}^{2}, \mathrm{~J} \mathrm{Chen}^{2}, \mathrm{Y} \mathrm{Sun}{ }^{2}$
}

\begin{abstract}
Objective: The study aimed to explore the correlation between urine interleukin (IL)-8, 6, 10, 17 levels and the efficacy of steroid in patients with idiopathic nephrotic syndrome (INS).
\end{abstract}

Methods: Forty-two INS patients were divided into steroid-sensitive (SS, $\mathrm{n}=15)$ and steroid-resistant $(\mathrm{SR}, \mathrm{n}=27)$ groups. One-year follow-up study was performed, in which urine and serum IL-8, 6, 10, 17 levels were detected after initial treatment, remission and relapse.

Results: Steroid-resistant patients showed higher urine and serum IL-8 level than SS patients after initial treatment, which declined during remission and enhanced after relapse; there were no differences in IL-6, 10, 17 levels between the two groups. Urine IL-6, 10, 17 levels in patients with podocytopathy were higher than that of patients with other pathological types, and SR patients with podocytopathy had higher urine IL-8 level than those in SS group. Logister regression analysis showed that there was only IL-8 levels that was related to the effects of hormone therapy. The area under the curve of ROC for prediction of steroid efficacy with urine and serum IL-8 level were 0.871 (95\% CI 0.63-0.921) and 0.633 (95\% CI 0.431-0.805), respectively.

Conclusion: Urine IL-8 level can serve as an indicator for steroid efficacy in INS patients.

Keywords: Idiopathic nephrotic syndrome, interleukin, steroid resistance, urine

From: ${ }^{1}$ Graduate School of Dalian Medical University, Dalian, China. ${ }^{2}$ Division of Nephrology, the First Hospital of Dalian Medical University, Dalian 116011, China.

Correspondence: Dr H Lin, Division of Nephrology, The First Hospital of Dalian Medical University No. 222 Zhongshan Road Xigang District, Dalian 116011, China. Fax: +86 411 836355956, e-mail honglilincn@163.com. 


\section{INTRODUCTION}

Glucocorticoid, the first choice drug for idiopathic nephrotic syndrome (INS) (1), exhibits individual variation in drug response; approximate $30 \sim 50 \%$ adult INS patients are steroid-resistant (SR) (2). Usually, combination immunosuppressant therapy is required for SR patients, $60 \sim 80 \%$ of whom can achieve remission but others are observed with persistent proteinuria which eventually leads to end-stage renal disease (3). So far, steroid is applied according to clinical experience and no biomarker has been discovered to predict and evaluate steroid efficacy due to its complex SR mechanism.

Research has shown that interleukin (IL) is involved in INS pathogenesis by increasing the permeability of glomerular basement membrane (GBM), glomerular cell proliferation and sclerosis (4). Some IL, such as IL-6 and 8, initiate nephritis and promote disease progression, while others, including IL-4 and 10, are important for self defense, inflammatory resolution and tissue repair in kidney. Recently, Liu et al and Massumoto et al have reported that IL-17 may be associated with INS pathogenesis $(5,6)$. Therefore, we performed a prospective study on INS to explore the changes in urine IL levels, aiming to discover the noninvasive indicators for predicting and dynamically monitoring steroid efficacy to serve in steroid therapy for INS.

\section{MATERIALS AND METHODS}

\section{Subject}

Forty-two INS patients treated in Department of Nephrology in the First Hospital of Dalian Medical University between Mar. 2011 and Dec. 2012 were selected. Inclusion criteria: 1) 18 
to 70 years old; 2) without steroid or immunosuppresant after first INS attack; 3) effectively controlled hypertension $(\leq 130 / 80 \mathrm{mmHg})$ or no hypertension; 4) ARB or ACEI drugs were administrated for more than eight weeks; 5) serum creatinine $\leq 200 \mathrm{umol} / \mathrm{L}$; 6) renal biopsy was performed routinely. Exclusion criteria: 1) secondary nephrotic syndromes such as lupus nephritis, Henoch-Schönlein purpura nephritis, diabetic nephropathy, cancer-associated nephropathies; 2) BMI $\leq 18$ or $\geq 25$; 3) $0.3 \sim 3$ g of 24-hour urine protein (24-HUP) after eight-week steroid treatment. Meanwhile, serum samples from 20 healthy people were used as control, whose ages, genders and race were corresponding to the patients. This study was conducted in accordance with the declaration of Helsinki. This study was conducted with approval from the Ethics Committee of the First Hospital of Dalian Medical University. Written informed consent was obtained from all participants. (ChiCTR-ONC-12002809; Chictr.org)

\section{Research methods}

All the subjects received glucocorticoid therapy, i.e. patients $<60$ years old: $500 \mathrm{mg} / \mathrm{d}$ methylprednisolone was intravenously injected for three days, continued with $40 \mathrm{mg} / \mathrm{d}$ oral prednisone (or the same oral dose of methylprednisolone tablets); patients $\geq 60$ years old: 250 $\mathrm{mg} /$ day methylprednisolone was intravenously injected for three days, continued with 30 $\mathrm{mg} / \mathrm{d}$ oral prednisone (or the same oral dose of methylprednisolone tablets). Eight weeks after sequential steroid therapy, the prednisone dose was tapered using 2.5 -mg decrements every 2 weeks until it reached $10 \mathrm{mg} / \mathrm{d}$, and this dose was maintained for 8 weeks until drug withdrawal. The patients with $24-\mathrm{HUP} \leq 0.3 \mathrm{~g}$ and serum albumin $\geq 35 \mathrm{~g} / \mathrm{L}$ was defined as steroid-sensitive (SS, $\mathrm{n}=15$ ) group; patients whose 24-HUP was not improved or the 
reduction was less than 50\% compared with baseline and serum albumin $<35 \mathrm{~g} / \mathrm{L}$ was defined as SR group ( $\mathrm{n}=27)$, in which tacrolimus was also initially applied at a dose of $0.05 \mathrm{mg} / \mathrm{Kg}$.d, blood drug concentration maintained at $4 \sim 7 \mathrm{ng} / \mathrm{mL}$; treatment was performed for half year in patients with complete remission (CR) and one year in patients with partial remission (PR). General conditions and the following indicators of the patients were recorded: serum albumin, creatinine, cholesterol and 24-HUP were performed by the facilities' usual laboratory. Measurement of urinary N-acetyl- $\beta$-(D)-glucosaminidase/creatinine $\quad$ (NAG/Cre), microalbuminuria/creatinine (MA/Cre), urine beta-2 microglobulin/creatinine $\left(\beta_{2} \mathrm{MG} / \mathrm{Cre}\right)$ and urine alpha-1 microglobulin/urinary creatinine $\left(\alpha_{1} \mathrm{MG} / \mathrm{Cre}\right)$ were performed using the scattering immunonephelometry.

All the patients were followed up for one year; their morning urine and serum samples were collected during initial treatment, remission (CR and PR) and relapse. The samples were centrifuged at $2000 \mathrm{~g}$ for $10 \mathrm{~min}$. The supernatant was preserved in $-70{ }^{\circ} \mathrm{C}$ and the IL-6, 8, 10, 17 levels were evaluated using ELISA (kits were bought from R\&D System, Minneapolis, MN, USA). CR is defined as the urine protein $\leq 0.3 \mathrm{~g} / 24 \mathrm{~h}$ and the serum albumin $\geq 35 \mathrm{~g} / \mathrm{L}$ during three consecutive measurements. PR is defined as the reduction of urine protein $\geq 50 \%$ and the serum albumin $\geq 35 \mathrm{~g} / \mathrm{L}$ during three consecutive measurements. Among patients at remission, one would be defined with relapse if his/her urine protein increase $\geq 30 \%$ and could not be reduced in two weeks, excluding fatigue or inflammation, etc. Podocytopathy, including minimal change disease (MCD), membranous nephropathy (MN), focal segmental glomerulosclerosis (FSGS), is defined as previously described, namely the main features of glomerular disease exhibited that the number of glomerular podocytes 
reduced, the basal membrane thickened, the glomerular matrix components changed and the foot process fused (7).

\section{Statistical analysis}

Data was analyzed with SPSS18.0. Normally distributed measurement data was presented as Mean \pm SEM; comparison between two groups utilized t-test; comparison among multiple groups used one-way analysis of variance (ANOVA). Skewed distributed measurement data was presented as median and quartiles; comparison between two groups employed Mann-Whitney U test; comparison among multiple groups used Kruskal-Wallis $\mathrm{H}$ test. Enumeration data was presented as constituent ratio or percentage, and data comparison utilized $\chi^{2}$ test. Unconditional logistic regression modeling was performed to determine the correlation between cytokines levels and steroid effacy. Meanwhile, the curves of receiver operating characteristic (ROC) were plotted to calculate the sensitivity, specificity and area under the curve (AUC). $P<0.05$ was considered significantly different.

\section{RESULTS}

\section{Participation result}

After eight-week steroid therapy, 25 patients with $0.3 \sim 3 \mathrm{~g}$ of 24 -HUP were excluded from 80 participants, and the remaining patients were divided into SS $(n=25)$ and SR $(n=30)$ groups. Pulmonary infection ( $n=4$ vs $n=1)$, urinary tract infection $(n=3$ vs $n=2)$ and loss to follow-up $(\mathrm{n}=3$ vs $\mathrm{n}=0$ ) were observed in SS and SR groups. Finally, 15 SS patients including three cases of relapse, and 27 SR patients including 20 cases of remission in one year, among 
which seven patients had recurrence, were followed up in our study (Fig. 1).

\section{Clinical and pathological data}

There were no statistical differences in gender, age, albumin, creatinine, cholesterol, 24-HUP and MA/Cre between SS and SR groups, but SR group showed higher urine $\alpha_{1} \mathrm{MG} / \mathrm{Cre}$, $\mathrm{NAG} / \mathrm{Cre}$ and $\beta_{2} \mathrm{MG} / \mathrm{Cre}$ levels than SS group. Among routine pathological types, the proportion of $\mathrm{MN}$ increased and the proportion of MCD decreased in SR group compared with that of SS group; no significant differences in proportion of other pathological types were observed between two groups, as well as podocytopathy (MCD, MN and FSGS, Table $1)$.

\section{Initial urine levels of IL-6, 8, 10, 17 in healthy controls, SS and SR patients}

There were no statistical differences in initial urine levels of IL-6, 10, 17 among healthy controls, SS and SR patients, while urine IL-8 level was highest in SR group and higher in SS group than that of control group (Table 2).

\section{Urine and serum levels of IL-6, 8, 10, 17 in INS patients}

Urine and serum IL-8 level in INS patients significantly declined during remission compared with that after initial treatment and markedly enhanced after relapse; there were no differences in IL-6, 10, 17 levels among three stages in INS patients (Table 3).

\section{Correlation analysis}

Logister regression analysis showed that the urine and serum IL-8 levels were related with the hormone-sensitivity, while the other three kinds of cytokines had no association with the hormone therapy either in the urine or serum (Table 4). Urine IL-6, 8, 17 levels in patients with podocytopathy were higher than that of patients with other pathological types, but there 
was no statistical difference in urine IL-10 level (Fig. 2). SR patients with podocytopathy had higher urine IL-6, 8, 17 levels than others in SR group, no statistical difference in urine IL-10 level was observed. There were no differences in IL-6, 8, 10, 17 levels between SS patients with podocytopathy and other SS patients. Patients with podocytopathy in SR group had higher urine IL-6, 8, 17 levels than those in SS group, especially for IL-8 level (Table 5).

\section{Prediction of steroid efficacy}

The AUC of ROC for prediction of steroid efficacy with urine IL-8 level was shown in Table 6; the optimal cutoff value that maximized (sensitivity+specificity) was $123.88 \mathrm{pg} / \mathrm{ml}$. Urine IL-8 levels in SS and SR groups were $(65.86 \pm 15.08) \mathrm{pg} / \mathrm{ml}$ and $(79.28 \pm 31.61) \mathrm{pg} / \mathrm{ml}$, respectively; the optimal cutoff value was $57.71 \mathrm{pg} / \mathrm{ml}$.

\section{DISCUSSION}

Steroid-resistance is always a challenge in INS treatment. Clinically, several indicators, such as renal pathology, urinary protein, and renal function, are used to preliminarily assess renal lesion degree and its prognosis. Nowadays, no effective biomarker or the corresponding preventive treatment for steroid resistance has been found yet. Urine sample is used in our research to search more sensitive and specific biological indicator for early prediction of INS and monitoring steroid therapy response, because it is noninvasive, easy for large-scale repeated sampling and preserving, strongly practical in clinical trial, especially in dynamically monitoring disease process and evaluating the effect.

Our research indicated that the steroid efficacy was independent of gender, age and 
serum levels of albumin, creatinine and urine protein, but some urine protein indicators that were frequently used facilitated the evaluation of steroid efficacy in INS patients $(8,9)$. We found that $\alpha_{1} \mathrm{MG} / \mathrm{Cre}, \beta_{2} \mathrm{MG} / \mathrm{Cre}$ and $\mathrm{NAG} / \mathrm{Cre}$ levels in SR group were significantly higher than that of SS group. However, since these three indicators mainly reflected the degree of tubulointerstitial lesion, the value of predicting steroid sensitivity still requires further investigation.

IL-8, mainly from lipopolysaccharide activated monocytes, antigen or phytohaemagglutinin activated $\mathrm{T}$ cells and resident kidney cells, serves as an important mediator of inflammatory diseases, causes accumulation and activation of inflammatory cells in kidney and aggravates renal pathological lesion (10). Moreover, by affecting the metabolism of sulfide in glomerular basement membrane, IL-8 alters its anionic charge barrier and induces proteinuria (11). Some research has demonstrated that IL-8 is positively correlated with urine protein level, and urine IL-8 level increases by 2.9 times once relapse is observed in INS patients at remission (12). Meanwhile, the IL-8 mRNA expression level in peripheral blood mononuclear cells increases significantly, indicating IL-8 might be important in INS pathogenesis (13). Our research showed that urine IL-8 level was significantly higher in INS patients than that of healthy controls, and in SR patients than that of SS patients. Urine and serum IL-8 level significantly declined after remission, and enhanced after relapsed, suggesting the correlation between urine and serum IL- 8 level and steroid efficacy, which was also proved by logistic regression; urine and serum levels of the other three cytokines were independent of steroid efficacy and INS progression, thus unable to serve as indicators for steroid efficacy in the treatment for INS. We also evaluated serum 
IL-8 level for the prediction of steroid efficacy, and the AUC of urine IL-8 was significantly larger than that of serum IL-8, with more specificity, indicating urine IL-8 level more accurately predicted the steroid efficacy in INS patients than serum IL-8 level.

At present, steroid efficacy in INS patients is mainly assessed according to conventional renal pathological type. However, no evidence confirms their correlation (14). Among INS patients, $5 \sim 15 \%$ of MCD, $50 \%$ of FSGC, $95 \%$ of $\mathrm{MN}$ and $50 \%$ of MPGN are characterized by steroid-resistance (15). Our research indicated that MCD (60\%) and MN (59\%) were predominant in SS group and SR group, respectively. In addition, 10\% (1/10) of MCD was SR patient and $11.1 \%(2 / 18)$ of MN was SS patient, which could not be explained with the discrepancy in routine pathological types. Podocyte injury is the main cause of proteinuria in INS patients (16). Podocytopathy, first proposed by Pollak, includes MCD, FSGC and MN, which are observed with obvious anomalies in podocyte morphology and function $(7,17)$. Our previous study has revealed that the degree of podocyte injury facilitates the evaluation of steroid efficacy in INS patients, i.e. patients with severe podocyte injury are poorly sensitive to steroid (18). We discovered that urine IL-6, 8 levels in patients with podocytopathy significantly elevated compared with that of patients with other pathological type. Moreover, podocyte can secret IL-6, 8 (19), thus the increase in urine IL-6,8 levels is considered to be related to podocyte injury. Further investigation showed that SR patients with podocytopathy had higher urine IL-6, 8 levels than SS patients, which also suggested that the proinflammatory effect of IL-6, 8 may be involved in SR pathogenesis in patients with podocytopathy.

IL-17, produced by Th17 cells, participates in inflammatory response by binding 
membrane IL-17 receptors on endothelial and epithelial cells (20). Our research displayed that urine IL-17 level was similar in SR and SS groups, but higher in patients with podocytopathy than that of patients with other pathological type and also higher in SR patients with podocytopathy compared with that of SS patients with podocytopathy. Further investigation is required by expanding sample size to clarify the relationship between IL-17, podocyte injury and steroid-sensitivity.

Due to limited sample size, we only explored the relationship between urinary cytokine level and steroid efficacy in patients with podocytopathy, without further analysis of specific pathological type. In addition, long-term follow-up is required in further study, which will focus on the application of IL-8 combined with conventional small-molecule protein as a noninvasive biomarker in predicting steroid sensitivity in INS patients.

\section{ACKNOWLEDGEMENTS}

This study was supported by grants from the General Program of National Natural Science Foundation of China (No. 81200522) and State Key Clinical Specialty Construction Project.

\section{AUTHORS' NOTE}

The authors declare no conflict of interest regarding this paper. 


\section{REFERENCES}

1. Greenbaum LA, Benndorf R, Smoyer WE. Childhood nephrotic syndrome --current and future therapies. Nat Rev Nephrol 2012; 8: 445-58.

2. Hodson EM, Knight JF, Willis NS, Craig JC. Corticosteroid therapy in nephrotic syndrome: a meta- analysis of randomised controlled trials. Arch Dis Child 2000; 83: $45-51$.

3. Tang X, Xu F, Chen DM, Zeng CH, Liu ZH. The clinical course and long-term outcome of primary focal segmental glomerulosclerosis in Chinese adults. Clin Nephrol 2013; 80: $130-9$.

4. Srivastava T, Sharma M, Yew KH, Sharma R, Duncan RS, Saleem MA, et al. LPS and PAN-induced podocyte injury in an in vitro model of minimal change disease: changes in TLR profile. J Cell Commun Signal 2013; 7: 49-60.

5. Liu LL, Qin Y, Cai JF, Wang HY, Tao JL, Li H, et al. Th17/Treg imbalance in adult patients with minimal changenephrotic syndrome. Clin Immunol 2011; 139: 314-20.

6. Matsumoto K, Kanmatsuse K. Increased urinary excretion of interleukin-17 in Nephrotic Patients. Nephron 2002; 91: 243-9.

7. Pollak MR. Inherited podocytopathies: FSGS and nephrotic syndrome from a genetic viewpoint. J Am Soc Nephrol 2002; 13: 3016-23.

8. Fede C, Conti G, Chimenz R, Ricca M. N-acetyl-beta-D-glucosaminidase and beta2microglobulin: prognostic markers in idiopathic nephrotic syndrome. J Nephrol 1999; 12: $51-5$.

9. Mishra OP, Jain P, Srivastava P, Prasad R. Urinary N-acetyl-beta-D glucosaminidase 
(NAG) level in idiopathic nephrotic syndrome. Pediatr Nephrol 2012; 27: 589-96.

10. Garin EH, Blanchard DK, Matsushima K. IL-8 production by peripheral blood mononuclear cells in nephritic patients. Kidney Int 1994; 45: 1311-7.

11. Garin EH, West L, Zheng W. Effect of interleukin-8 on glomerular sulfated compounds and albuminuria. Pediatr Nephrol 1997; 11: 274-9.

12. Souto MF, Teixeira AL, Russo RC, Penido MG, Silveira KD, Teixeira MM, et al. Immune mediators in idiopathic nephrotic syndrome: evidence for a relation between interleukin 8 and proteinuria. Pediatr Res 2008; 64: 637-42.

13. Laflam PF, Haraguchi S, Garin EH. Cytokine mRNA profile in lipoid nephrosis: evidence for increased IL-8 mRNA stability. Nephron 2002; 91: 620-6.

14. Dumoulin A, Hill GS, Montseny JJ, Meyrier A. Clinical and morphological prognostic factors in membranous nephropathy: significance of focal segmental glomerulosclerosis. Am J Kidney Dis 2003; 41: 38-48.

15. Woroniecki RP, Orlova TN, Mendelev N, Shatat IF, Hailpern SM, Kaskel FJ, et al. Urinary protein of steroid-sensitive and steroid-resistant idiopathic nephrotic syndrome of childhood. Am J Nephrol 2006; 26: 258-67.

16. Shankland SJ. The Podocyte's response to injury: role in proteinuria and glomerulosclerosis. Kidney Int 2006; 69: 2131-47.

17. Imasawa T, Rossignol R. Podocyte energy metabolism and glomerular diseases. Int J Biochem Cell Biol 2013; 45: 2109-18.

18. Xie H, Lin HL, Chen JL. Correlation of expression of glucocorticoid receptor $\alpha$ and $\beta$ in podocytes with sensitivity of glucocorticoid in primary nephrotic syndrome. China $\mathrm{J}$ 
Modern Med 2012; 36: 35-9.

19. Xing CY, Saleem MA, Coward RJ, Ni L, Witherden IR, Mathieson PW. Direct effects of dexamethasone on human podocytes. Kidney Int 2006; 70: 1038-45.

20. Kiliś-Pstrusińska K, Zwolińska D, Medyńska A, Wawro A, Kordecki H. Interleukin-17 concentration in serum and urine of children with idiopathic nephrotic syndrome. Przegl Lek 2006; 63 Suppl 3: 198-200. 
Table 1 Clinical and pathological data of SS and SR patients

\begin{tabular}{|c|c|c|c|}
\hline & $\mathrm{SS}(\mathrm{n}=15)$ & $\operatorname{SR}(n=27)$ & $P$ for Trend \\
\hline Gender (M/F) & $9 / 6$ & $11 / 16$ & 0.963 \\
\hline Age (years) & $45.3 \pm 19.8$ & $48.0 \pm 14.2$ & 0.597 \\
\hline Albumin $(\mathrm{g} / \mathrm{L})$ & $22.5 \pm 4.2$ & $24.1 \pm 2.4$ & 0.13 \\
\hline Creatinine $(\mu \mathrm{mol} / \mathrm{L})$ & $62.0(60.0-68.0)$ & $63.0(57.0-78.5)$ & 0.973 \\
\hline Cholesterol (mg/dl) & $303.8 \pm 78.3$ & $344.2 \pm 103.9$ & 0.282 \\
\hline 24-HUP (g) & $7.8 \pm 3.1$ & $7.3 \pm 2.6$ & 0.608 \\
\hline$\alpha_{1} \mathrm{MG} / \mathrm{Cre}(\mathrm{mg} / \mathrm{g})$ & $25.9(20.8-27.8)$ & $43.5(24.1-62.6)$ & 0.029 \\
\hline \multirow[b]{2}{*}{ MA/Cre (mg/g) } & 3130.0 & 2975.0 & \multirow[b]{2}{*}{0.073} \\
\hline & $(3070.0-4870.0)$ & $(2334.3-3700.0)$ & \\
\hline NAG/Cre (U/g) & $24.7(20.1-29.2)$ & $37.6(33.8-40.6)$ & 0.003 \\
\hline$\beta_{2} \mathrm{MG} / \mathrm{Cre}(\mathrm{mg} / \mathrm{g})$ & $1.0(0.9-1.2)$ & $1.4(1.1-1.5)$ & 0.002 \\
\hline \multicolumn{4}{|l|}{ Pathological types } \\
\hline MCD & $9(60 \%)$ & $1(4 \%)$ & 0.034 \\
\hline $\mathrm{MN}$ & $2(13 \%)$ & $16(59 \%)$ & 0.004 \\
\hline FSGS & $1(7 \%)$ & $2(7.5 \%)$ & 0.472 \\
\hline $\operatorname{IgAN}$ & $1(7 \%)$ & $2(7.5 \%)$ & 0.521 \\
\hline MPGN & $2(13 \%)$ & $6(22 \%)$ & 0.075 \\
\hline
\end{tabular}

Data presented as mean \pm standard deviation was analyzed with $\mathrm{t}$ test; data presented as median, quartile or percentage was analyzed with Mann-Whitney U test.

MCD, minimal change disease; MN, membranous nephropathy; FSGS, focal segmental glomerulosclerosis; IgAN, immunoglobulin A nephropathy; MPGN, mesangial proliferative glomerulonephritis. 
Table 2: Initial urine levels of IL-6, 8, 10, 17 in healthy controls, SS and SR patients (pg/ml)

\begin{tabular}{lllll}
\hline & Control & group & & \\
& & & & \\
& & SS group $(\mathrm{n}=15)$ & SR group $(\mathrm{n}=27)$ & $P$ value \\
IL-6 & 82.06 & 79.33 & 84.21 & \\
& & & & 0.091 \\
IL-8 & $(73.27-82.78)$ & $(75.49-86.69)$ & $(78.16-94.15)$ & \\
IL-10 & $78.32 \pm 11.54$ & $104.48 \pm 20.49$ & $135.12 \pm 27.96$ & $<0.01$ \\
IL-17 & $53.79 \pm 6.72$ & $55.52 \pm 13.39$ & $58.42 \pm 10.43$ & 0.471 \\
& $7.77 \pm 0.59$ & $8.11 \pm 1.58$ & $8.93 \pm 1.35$ & 0.061
\end{tabular}

Data presented as mean \pm standard deviation was analyzed with one-way ANOVA; data presented as quartile or percentage was analyzed with Kruskal-Wallis H test.

Table 3 Urine and serum levels of IL-6, 8, 10, 17 after initial treatment, remission and relapse $(\mathrm{pg} / \mathrm{ml})$

\begin{tabular}{llllll}
\hline Index & & Initial & Remission & Relapse & $P$ value \\
\hline \multirow{2}{*}{ IL-6 } & Urine & $80.5 \pm 9.45$ & $75.15 \pm 11.06$ & $79.64 \pm 14.68$ & 0.56 \\
& Serum & $88.37 \pm 40.19$ & $85.53 \pm 36.29$ & $80.35 \pm 36.89$ & 0.62 \\
IL-8 & Urine & $115.61 \pm 27.29$ & $74.57 \pm 27.07$ & $126.05 \pm 27.56$ & $<0.01$ \\
& Serum & $154.93 \pm 65.15$ & $89.07 \pm 65.96$ & $100.77 \pm 63.28$ & $<0.01$ \\
IL-10 & Urine & $57.34 \pm 11.68$ & $49.19 \pm 10.33$ & $55.93 \pm 16.11$ & 0.337 \\
& Serum & $64.38 \pm 22.73$ & $51.84 \pm 23.41$ & $57.66 \pm 34.66$ & 0.12 \\
IL-17 & Urine & $8.65 \pm 1.63$ & $9.30 \pm 1.24$ & $10.18 \pm 1.05$ & 0.13 \\
& Serum & $35.87 \pm 16.25$ & $29.79 \pm 16.97$ & $34.75 \pm 16.41$ & 0.21 \\
\hline
\end{tabular}

Data presented as mean \pm standard deviation was analyzed with one-way ANOVA. 
Table 4: The correlation between urine and serum initial levels of IL-6, 8, 10, 17 and steroid efficacy

\begin{tabular}{ccccc}
\hline \multicolumn{2}{c}{ Index } & Odd ratio & $95 \%$ CI & $P$ value \\
\hline \multirow{2}{*}{ IL-8 } & Urine & 1.03 & $1.01-1.05$ & 0.02 \\
& Serum & 1.02 & $1.01-1.04$ & 0.02 \\
IL-10 & Urine & 1.01 & $0.99-1.02$ & 0.09 \\
& Serum & 0.97 & $0.94-1.00$ & 0.07 \\
IL-6 & Urine & 1.01 & $0.96-1.06$ & 0.69 \\
& Serum & 0.97 & $0.96-0.99$ & 0.06 \\
& & & $0.97-1.02$ & 0.63 \\
\hline
\end{tabular}

95\% CI: 95\% Confidence interval 
Table 5 Comparison of urine IL-6, 8, 10, 17 levels at baseline in patients with podocytopathy between SS and SR groups (pg/ml)

\begin{tabular}{llllll}
\hline Index & SS & \multicolumn{2}{c}{ SR } & $P$ \\
& $\begin{array}{l}\text { Podocytopathy } \\
(\mathrm{n}=12)\end{array}$ & $\begin{array}{l}\text { Other pathological } \\
\text { types }(\mathrm{n}=3)\end{array}$ & $\begin{array}{l}\text { Podocytopathy } \\
(\mathrm{n}=19)\end{array}$ & $\begin{array}{l}\text { Other pathological } \\
\text { types }(\mathrm{n}=8)\end{array}$ & $\begin{array}{l}P \\
\text { value }\end{array}$ \\
\hline IL-6 & $79.94 \pm 7.83$ & $78.40 \pm 1.98$ & $89.50 \pm 13.80$ & $79.08 \pm 7.02$ & 0.023 \\
IL-8 & $105.03 \pm 22.97$ & $109.12 \pm 11.20$ & $144.66 \pm 26.65$ & $114.85 \pm 19.12$ & $<0.001$ \\
IL-10 & $56.90 \pm 14.32$ & $53.30 \pm 4.89$ & $56.94 \pm 10.72$ & $61.59 \pm 9.67$ & 0.993 \\
IL-17 & $8.46 \pm 1.58$ & $6.97 \pm 0.51$ & $9.49 \pm 1.19$ & $7.74 \pm 0.81$ & 0.035 \\
\hline
\end{tabular}

One-way ANOVA was used for statistical analysis. $P$ represented the comparison in patients with podocytopathy between SS and SR groups.

Table 6 Comparison of the AUC of ROC for prediction of steroid efficacy with urine and serum IL-8 level

\begin{tabular}{llllll}
\hline & Sensitivity & Specificity & AUC & $95 \%$ CI & Standard error \\
\hline Urine IL-8 & $72.0 \%$ & $86.7 \%$ & 0.871 & $0.663-0.921$ & 0.066 \\
Serum IL-8 & $85.7 \%$ & $57.1 \%$ & 0.633 & $0.431-0.805$ & 0.106 \\
\hline
\end{tabular}

95\% CI: 95\% confidence interval 


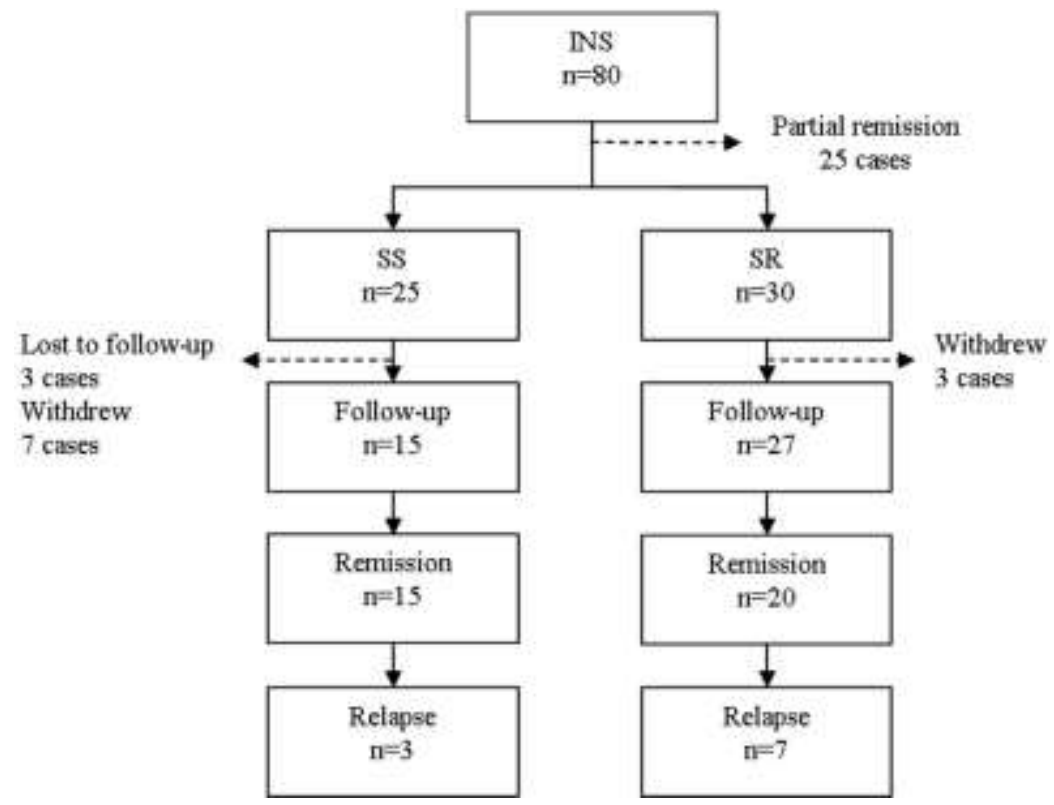

Fig. 1: Flow chart of INS patient participation.
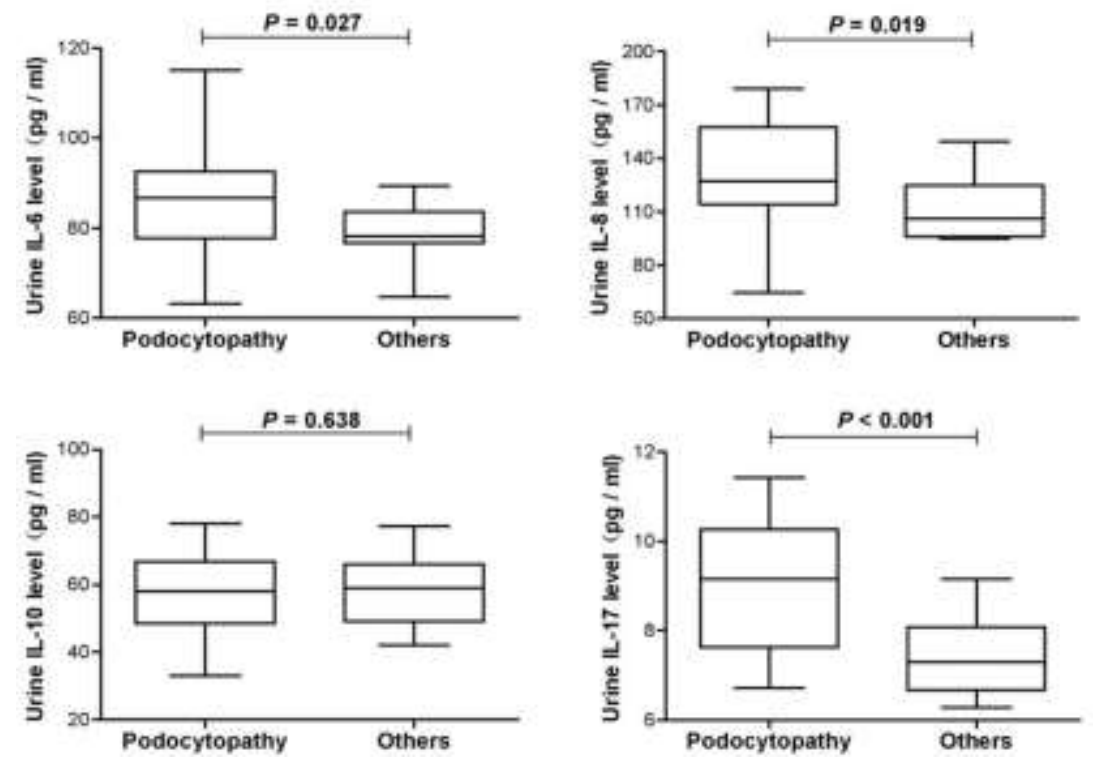

Fig. 2: Comparison of urine IL-6, 8, 10, 17 levels at baseline between patients with podocytopathy and patients with other pathological types. 